\title{
Assessment of covalent bond formation between coupling agents and wood by FTIR spectroscopy and pull strength tests
}

Rasmussen, Jonas Stensgaard; Barsberg, Søren Talbro; Venås, Thomas Mark; Felby, Claus

\section{Published in:}

Holzforschung

DOI:

10.1515/hf-2013-0121

Publication date:

2014

\section{Document version}

Early version, also known as pre-print

Citation for published version (APA):

Rasmussen, J. S., Barsberg, S. T., Venås, T. M., \& Felby, C. (2014). Assessment of covalent bond formation between coupling agents and wood by FTIR spectroscopy and pull strength tests. Holzforschung, 68(7), 799805. https://doi.org/10.1515/hf-2013-0121 


\section{Assessment of covalent bond formation between coupling agents and wood by FTIR spectroscopy and pull strength tests}

\begin{abstract}
In the focus was the question whether metal alkoxide coupling agents - titanium, silane, and zirconium - form covalent bonds to wood and how they improve coating adhesion. In a previous work, a downshift of the lignin infrared (IR) band $\sim 1600 \mathrm{~cm}^{-1}$ was shown to be consistent with the formation of ether linkages between lignin and titanium coupling agent. In the present work, changes were found in the attenuated total reflectance-Fourier transform IR (ATR-FTIR) spectra of lignin and wood mixed with silane, and titanium coupling agents, and to a lesser extent for a zirconium coupling agent. This was seen as evidence for covalent bonds between lignin phenolics and the coupling agents. No spectral changes were observed when the coupling agents were mixed with the wood constituents cellulose and hemicellulose. For verification of the results, a modified EN 311 wet adhesion pull strength test was performed with softwood panels painted with a solvent-borne alkyd/acrylic coating. The results revealed an improved adhesion for all tested coupling agents compared to the untreated reference. The spectroscopic and pull test results underline that the presence of the lignin moiety in wood is of central importance for improved wood coating adhesion.
\end{abstract}

Keywords: ATR-FTIR, coupling agents, covalent bonds, metal alkoxides, wood coating adhesion

\footnotetext{
*Corresponding author: Jonas S. Rasmussen, Faculty of Science, University of Copenhagen, Rolighedsvej 23, 1958 Frederiksberg C, Denmark, e-mail: jonas.s.rasmussen@gmail.com

Søren Barsberg and Claus Felby: Faculty of Science, University of Copenhagen, Rolighedsvej 23, 1958 Frederiksberg C, Denmark Thomas Mark Venås: Danish Technological Institute, Gregersensvej 1, 2630 Taastrup, Denmark
}

\section{Introduction}

The wood coating industry has to phase out hazardous chemicals and volatile organic compounds and to replace them with environment-friendly components (Preston
2000; Freeman et al. 2003; Directive 2004/42/CE 2004; Schultzetal.2007; Bulianand Graystone2009).Problematic is, however, the poor performance of new coating formulations concerning adhesion and service life. One obstacle for developing new and longer-lasting formulations is the lack of reliable and rapid test methods (Underhaug et al. 1983; Williams et al. 1990, 1999; Ahola 1993; Hjort and Bok 2010).

Adhesion can be improved by the use of coupling agents. Recently, Rasmussen et al. (2013) showed that a position downshift of the aromatic lignin infrared (IR) band from 1600 to $1586 \mathrm{~cm}^{-1}$ was triggered by covalent bond formations between lignin and titanium alkoxide (TA). These findings were made by attenuated total reflectance-Fourier transform IR (ATR-FTIR) spectroscopy and were supported by density functional theory (DFT) calculations based on appropriate model compounds.

In the context of metal alkoxides as coupling agents for wood coating, one or several end groups of the metal alkoxides are hydrolyzed and the hydroxyl functionality is thus expected to react with lignin hydroxyl groups. The remaining non-reacted functionalities (hydrocarbons) interact and entangle with the subsequently applied coating layer. The metal alkoxides thus act as mediating or coupling agents between the hydrophilic wood surface and the hydrophobic wood coating. It is believed that metal alkoxides with a similar chemistry as titanium, zirconium, or silane possess the same ability to react with lignin.

The coupling agents chosen for this study are isooctanol hydrogen phosphate zirconium complex (ZA), dimethyloctadecyl[3-(trimethoxysilyl)propyl]ammonium chloride (SA), and titanium triisostearoylpropoxide (TA) (Figure 1). The proposed chemistry for TA occurs by a surplus of water by which TA splits off its labile isopropyl group as isopropyl alcohol. The hydrolyzed TA possessing reactive groups then supposedly forms covalent bonds with lignin in the form of ether linkages and the remaining hydrocarbon groups are available for non-covalent interactions with a subsequent coating layer (Rasmussen et al. 2013). The chemistry for SA is somehow identical, only with the difference that the methoxy groups are split off 


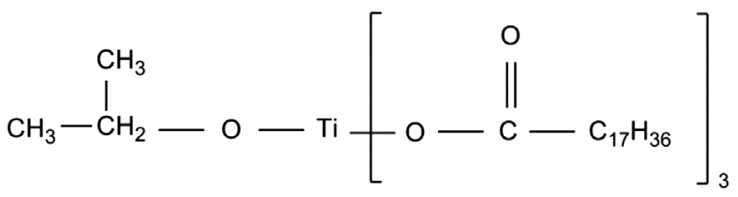

TA: Titanium triisostearoylpropoxide<smiles>C=CCOCC(CC)(CO[Z]OP(=O)(CCCC)OCC)COCC=C</smiles>

ZA:Isooctanol hydrogen phosphate zirconium complex<smiles>CO[Si](CCC(C)(C)[N+](C)(C)[18F])(OC)OC</smiles>

SA: Dimethyloctadecyl[3-(trimethoxysilyl)propyl]ammonium chloride

Figure 1 Name and chemical structure of the coupling agents.

in the form of methanol. The reaction leaves three hydrolyzed side groups and one hydrocarbon group (Figure 2c and d). The chemistry for ZA is more speculative. ZA is a large complex, and when it is hydrolyzed, the non-phosphate-containing side group will be split off, leaving a zirconium complex with three-alkoxide hydrocarbons.

From a point of view of applied science, it is important to know if the potential coupling agents actually improve wood coating adhesion. Therefore, the performance of the coupling agents should be tested by wet adhesion pull strength test. Often, the fracture surface of an adhesion pull strength test occurs in the glue line or panel instead of the desired fracture in the coating/wood interface. In order to promote the fracture surface between coating and wood, the coating adhesion to the panel can be weakened by soaking the panels in water. In this work, a slightly modified EN 311 (2002) wet adhesion pull strength test has been applied. The test enables a pull strength test where failure occurs solely in the coating-wood interface with a relatively low variation between test results from the same panel.

The aim of this study is to investigate the ATR-FTIR spectral effects of SA and ZA in a mixture with lignin and SA, ZA, and TA in mixtures with cellulose and hemicelluloses. Analogous investigations will be made for wood surfaces treated with SA, ZA, or TA, where ATR-FTIR spectroscopy provides surface specific chemical information. Finally, the expected improved coating adhesion should be measured by means of a modified wet adhesion pull strength test. The results of the adhesion tests and ATR-FTIR spectroscopy will be compared and discussed.

\section{Materials and methods}

The TA and ZA (95\%, dissolved in isopropanol) were purchased from Ken-React (Bayonne, NJ, USA); the SA (95\%, dissolved in isopropanol) was purchased from Evonik Industries (Essen, Germany). $p$-xylene ( $\geq 99.0 \%$; VWR-Bie \& Berntsen, Herlev, Denmark) was the solvent for ATR-FTIR spectroscopy. Isopropanol $(\geq 99.0 \%)$ was from VWR-Bie \& Berntsen. Origins of other samples: Hardwood organosolv lignin was from Sigma-Aldrich A/S (Broendby, Denmark); xylan as representative for hemicelluloses (from beechwood, Fagus sylvatica L.) was obtained from Sigma-Aldrich A/S; and cellulose is a Whatman no. 1 filter paper from Frisenette Aps (Knebel, Denmark). Wood specimens of air-dried beechwood (F. sylvatica L.) were cut into 25 (long.) $\times 15$ (tang.) $\times 10 \mathrm{~mm}^{3}$ (rad.) pieces. Wood slices were cut by a microtome (Micron HM450; Thermo Scientific, Waltham, MA, USA) in the longitudinal direction with a thicknesses $\leq 40 \mu \mathrm{m}$. 
a<smiles>CC(C)(C)O[OH+]C(C)(C)C</smiles>

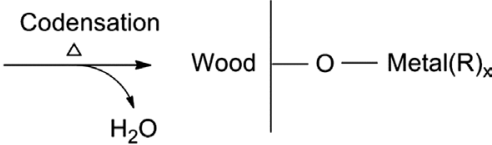

b

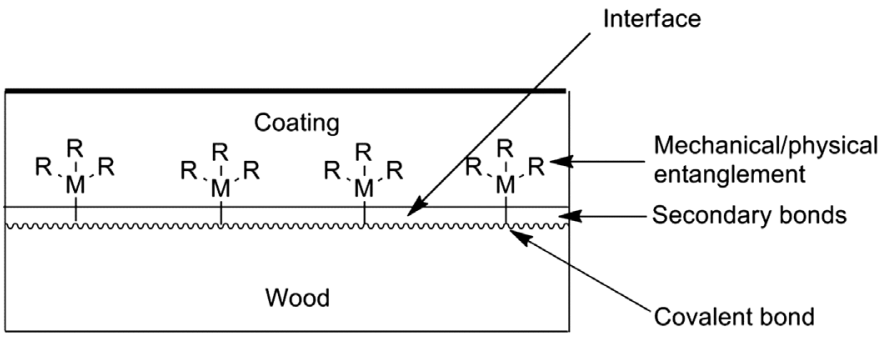

C

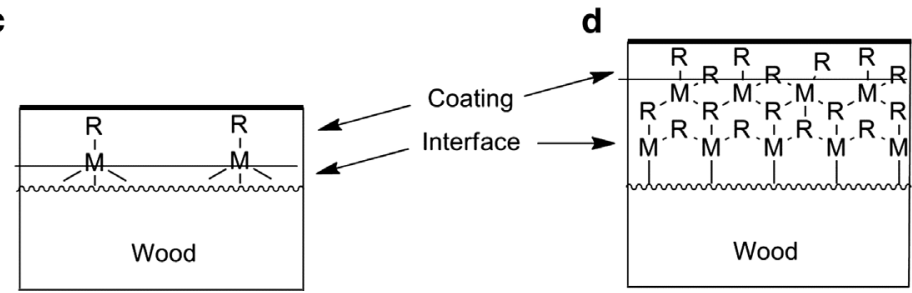

Figure 2 (a) Proposed chemical reaction between wood $\mathrm{OH}$ groups and a metal alkoxide where $\mathrm{x}=1-3$ is the number of functional groups. After the initial hydrolysis of the metal alkoxide, the following condensation results in ether bonds formation between the wood surface and metal alkoxide. (b) One covalent bond formed with wood with three hydrocarbons entangled into the coating film. (c) Three covalent bonds between wood and coupling agent with one hydrocarbon entangled into the coating film. (d) One covalent bond between wood and coupling agent, the coupling agents have formed complexes which entangles the coating film and creates a weak boundary layer between the wood surface and coating layer.

Scots pine (Pinus sylvestris L.) sapwood were sawn and planed to panels with a final dimension of $380 \times 105 \times 20 \mathrm{~mm}^{3}$ and the panels were graded low density $\left(\geq 500 \mathrm{~kg} \mathrm{~m}^{-3}\right)$, medium density $\left(500-600 \mathrm{~kg} \mathrm{~m}^{-3}\right)$, and high density ( $\left.\leq 650 \mathrm{~kg} \mathrm{~m}^{-3}\right)$ in accordance with EN 927-3 (2006). The longitudinal edges facing outward were rounded with sandpaper grid 100 and the panels were conditioned at $65 \%$ relative humidity at $20^{\circ} \mathrm{C}$ before use.

Treatment with coupling agents: Samples of TA, SA, and ZA were dissolved in $p$-xylene $(600 \mu \mathrm{l}, 2 \%$ concentration by volume) and contained in $2 \mathrm{ml}$ Eppendorf tubes with $25 \mathrm{mg}$ lignin, $25 \mathrm{mg}$ xylan, $25 \mathrm{mg}$ cellulose, or $100 \mathrm{mg}$ beech wood, respectively. The suspensions of these components (without coupling agent) in $600 \mu \mathrm{l}$ $p$-xylene served as references. To induce reaction, all samples were placed in an Eppendorf thermomixer at $T=95^{\circ} \mathrm{C}$ for $16 \mathrm{~h}$. The sample sets were then flushed five times with $1 \mathrm{ml} p$-xylene and finally airdried to remove non-complexed reactants.

ATR-FTIR spectroscopy was done as described by Rasmussen et al. (2013). Instrument: Thermo Scientific Nicolet 6700 FTIR spectrometer equipped with a temperature-adjustable ATR unit (Golden Gate) purged with dry air. Resolution: $4 \mathrm{~cm}^{-1} ; 64$ scans were coadded (the background considered of 128 scans). The samples were added at $80^{\circ} \mathrm{C}$ crystal temperature; then, the temperature was elevated to $120^{\circ} \mathrm{C}$. Each spectrum was measured after $p$-xylene evaporated (indicated by the complete disappearance of its characteristic IR bands). All spectra were baseline corrected by means of the Thermo Scientific Omnic 8 software.

Wet adhesion pull strength test: Each coupling agent was dissolved at $2 \%$ concentration in isopropanol and applied by spray to three-fourths of tangential panel surface $\left(80 \mathrm{ml} \mathrm{m}^{-2}\right)$ leaving onefourth of the panel as a reference. The panels were then dried at $103^{\circ} \mathrm{C}$ for $16 \mathrm{~h}$ followed by a spray paint by a commercially available solvent-borne and transparent alkyd/acrylic top coat. The coating was applied twice to the front side of the panel and once to the back side. The end grains and sides of the panels were sealed with seal paint. The panels were air-dried for $24 \mathrm{~h}$ between each treatment.

After drying, four steel dollies with a diameter of $35 \mathrm{~mm}$ were glued onto the painted surface of each panel and dried for $24 \mathrm{~h}$. Three dollies were glued to the part of the panel treated with coupling agent and the fourth was glued to the non-treated part of the panel. The glue was an in-house modified 2K Araldite. A $3 \mathrm{~mm}$ wide and deep groove was cut around the dollies. Each panel was submerged into water until the water uptake reached $18-22 \mathrm{~g}$ per panel.

The adhesion strength was tested according to EN 311 (2002). The pull strength test was performed with the instrument Instron 1195 (Norwood, MA, USA; fixed speed of $5 \mathrm{~mm} \mathrm{~min}^{-1}$ ). The pull strength of the reference dolly was set to $100 \%$ and the percentage-wise improvement was measured accordingly. A test panel was approved when the locus of failure for all steel dollies was situated entirely in the interface and the deviation between the dollies glued to the treated part of the panel did not exceed 15\%.

\section{Results and discussion}

\section{Spectra of coupling agents and lignin}

The formation of covalent bonds between lignin metal alkoxide is associated with a relative decrease of the lignin 
$\mathrm{OH}$ stretch band around $3400 \mathrm{~cm}^{-1}$ (Castellano et al. 2004) and changes of the characteristic aromatic lignin bands around $1600 \mathrm{~cm}^{-1}$ (Rasmussen et al. 2013). The changes for ZA-treated lignin $(\mathrm{ZA}+\mathrm{L})$ in Figure $3 \mathrm{~A}$ and $\mathrm{B}$ are small. The lignin aromatic bands $(2,3)$ appear unchanged, while a decrease of the $\mathrm{OH}$ band (1), a slight decrease of the lignin doublet band (2a), and a minor displacement of the band (2b) at $1606 \mathrm{~cm}^{-1}$ can be observed. On the contrary, for the $\mathrm{SA}$ reaction with lignin $(\mathrm{SA}+\mathrm{L})$ in Figure $3 \mathrm{C}$ and $\mathrm{D}$, the covalent bond formation is clearly evidenced with a significant decrease of the $\mathrm{OH}$ band (4) and position shifts of the lignin aromatic bands $(5,7)$ to $(6,8)$.

There are no changes in the spectra of carbohydrate polymers such as cellulose and hemicelluloses.

\section{Spectra of coupling agents and wood}

Spectra of wood shavings mixed with the coupling agents are shown in Figure 4. Although the wood spectrum also has contributions from cellulose and hemicelluloses, the characteristic lignin bands dominate the $1500-1600 \mathrm{~cm}^{-1}$ spectral range. The three spectra of treated wood shown in Figure 4A, C, and E are in all cases more complex compared to the treated lignin cases shown in Figure 3. The $\mathrm{OH}$ stretch band at $3400 \mathrm{~cm}^{-1}(9,14$, and 20) for the three coupling agents shows no clear changes (Figure 4B, D, and F). However, treatment with all agents splits the characteristic lignin band around $1510 \mathrm{~cm}^{-1}$ into two bands at 1515 and $1495 \mathrm{~cm}^{-1}$, that is, SA+wood (12) into (11) and (13); ZA+wood (18) into (17) and (19); and TA+wood (25) into (24) and (26). For the ZA+wood treatment, additional sharp bands also arise at 1614 and $1607 \mathrm{~cm}^{-1}(15$, 16). For all treatments, a number of other bands originate from the unreacted and/or self-condensed agent, for example, (24-26) for TA+wood and possibly (10) for SA+wood.

These observations of band splitting of the $1510 \mathrm{~cm}^{-1}$ band as well as new bands at 1614 and $1607 \mathrm{~cm}^{-1}$ are not seen for the lignin treatments. This indicates that an
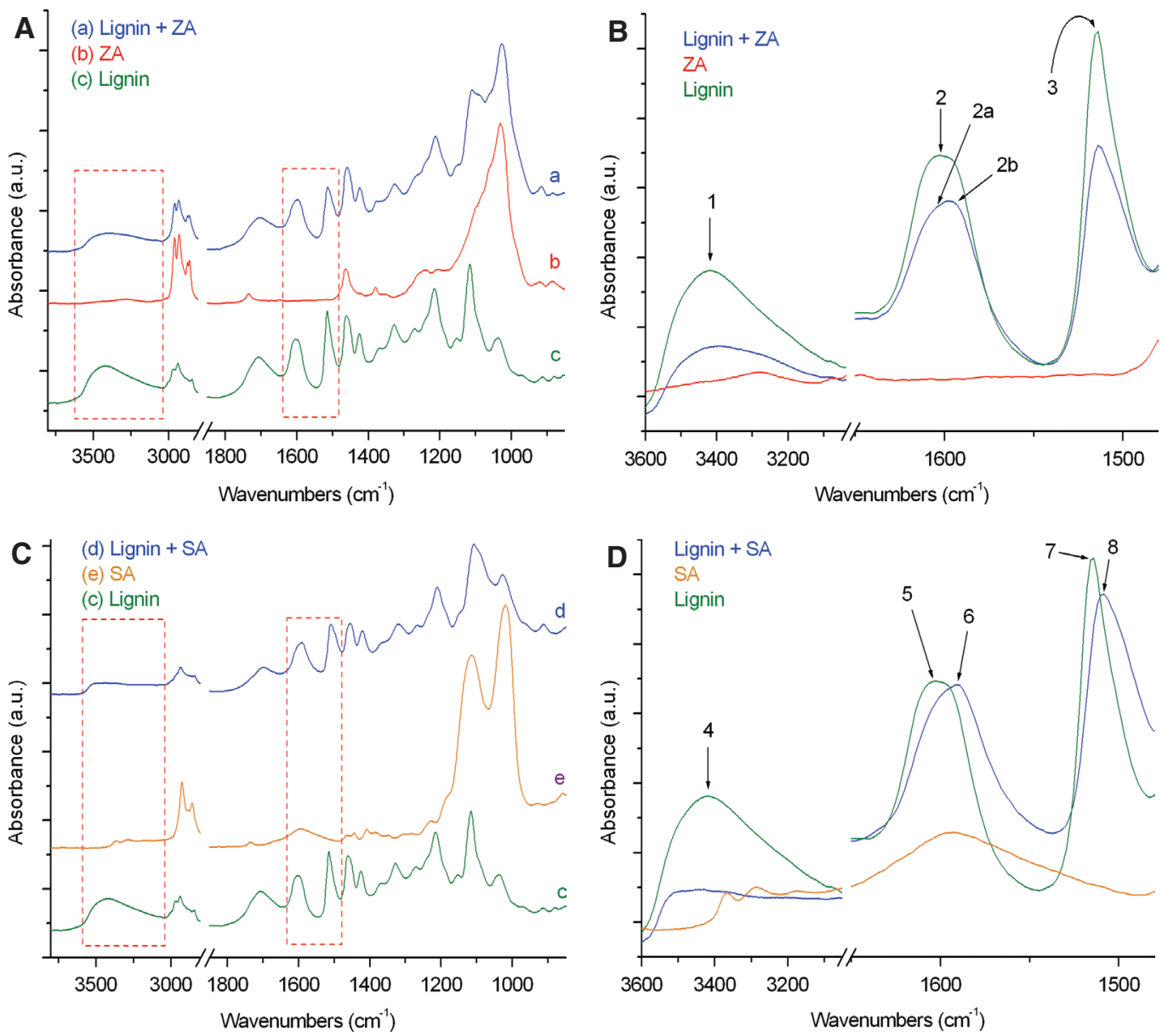

Figure 3 (A) and (C) FTIR spectra of ZA, SA, lignin, and their derivatives. (B) and (D) show a zoom of the spectral changes of organosolv lignin when mixed with $\mathrm{ZA}$ and $\mathrm{SA}$. 

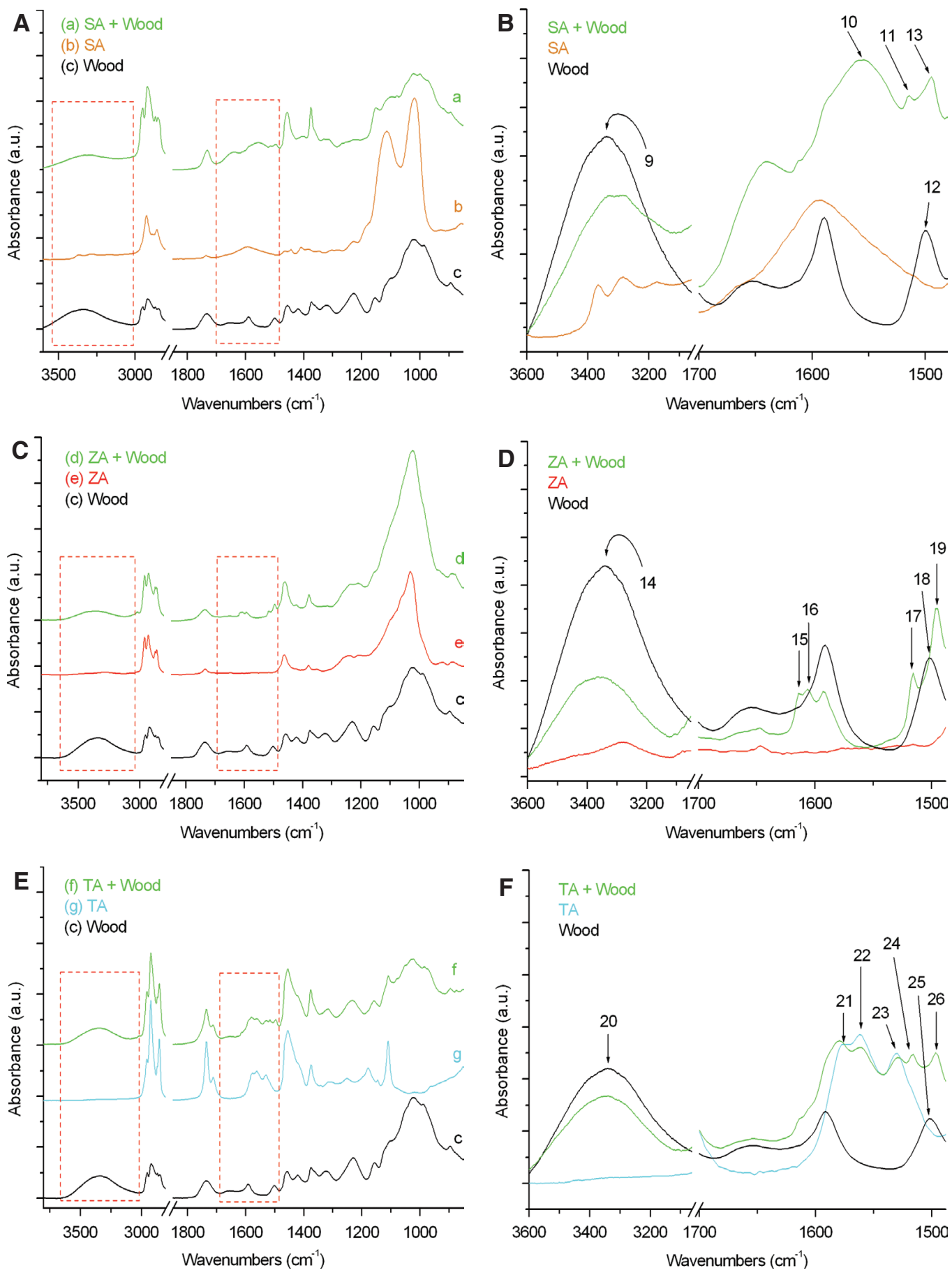

Figure 4 (A), (C) and (E) FTIR spectra of SA, ZA, TA, wood, and their derivatives. (B), (D), and (F) show a zoom of the spectral changes of wood when mixed with SA, ZA and TA.

industrial lignin may not be a good model of the specific reaction with wood surface lignin nor of its reactive moieties. However, in both cases, the ATR-FTIR results clearly demonstrate that the reactivity of metal alkoxides depends on the presence of lignin.

\section{Wet adhesion pull strength test}

The tensile strength improved in comparison to the reference test dollies with $30 \%, 36 \%$, and $37 \%$ for the additives ZA, SA, and, TA, respectively. The results are 
based on measurements of panels with high, medium, and low density. The panels were valid when the fractures of all dollies were in the interface leading to $n=27$; $n=9 ; \mathrm{k}=3, \mathrm{STDV}^{\mathrm{TA}}=0.15 ; \mathrm{STDV}^{\mathrm{SA}}=0.16 ; \mathrm{STDV}^{\mathrm{ZA}}=0.26$. The tensile strength variation between coupling agents can be explained by the natural variation between panels and the inhomogeneous nature of wood in general.

It is noted that coupling agent condensation can be affected by readily available water (Xie et al. 2010). The wetting of the panels may have caused hydrolysis of the coupling agents-lignin bonds and a reverse reaction. Thus, the real improvement of the coating adhesion is presumably much higher in a drier environment. However, additional work needs to be done for comparison of the strength results obtained by wet adhesion pull tests with service life improvement. The wet adhesion results are in line with the ATR-FTIR findings, where the most pronounced spectral changes were seen for SA and TA and to lesser extent ZA.

\section{Conclusion}

The ATR-FTIR spectra of cellulose and xylan showed no changes after mixture with the coupling agents. For industrial lignin, the SA agent caused changes (e.g., position shifts) of the aromatic lignin bands, where the ZA agent caused none or only small changes. For wood samples, all agents TA, ZA, and SA caused changes of the aromatic lignin bands, which seemed specific for the native wood lignin when compared to (denaturated) industrial lignin. New bands appeared at 1515 and $1495 \mathrm{~cm}^{-1}$ for wood samples treated with any of the coupling agents. This could be a sign of complex formation between the lignin phenolics and the agents, which changes the aromatic vibrations. Improved wet adhesion results were obtained by a pull-off test. Altogether, a 30-37\% better tensile strength was observed in the presence of metal alkoxides. The covalent bonding between metal alkoxide and lignin ensures that the functional groups of the all tested agents provide a strong layer with enhanced adhesion compatibility with a subsequently applied paint layer.

This work underlines the importance of lignin for the interaction of the coupling agents with the wood surface. More detailed investigations are needed to distinguish and optimize the reaction mechanism and efficiencies of the different metal alkoxide agents. From a point of view of applied science, it is recommendable to plane or sand wood surface before treatment with coupling agents in order to expose non-degraded lignin. Then, the panels must be heated to $>95^{\circ} \mathrm{C}$ for $\leq 16 \mathrm{~h}$ to ensure a reaction of the applied coupling agents with the surface lignin.

Acknowledgments: This work was supported by funding from the Danish National Advanced Technology Foundation.

Conflict of interest statement: The authors declare that they have no conflict of interest.

Received July 4, 2013; accepted January 21, 2014; previously published online February 19, 2014

\section{References}

Ahola, P. Chemical and physical changes in paints or painted wood due to ageing. Dissertation, Technical Research Centre, Finland, 1993.

Bulian, F., Graystone, J.A. (2009) Raw materials for wood coatings - solvents, additives and colorants. In: Wood Coatings: Theory and Practice. Elsevier, Amsterdam. pp. 95-137.

Castellano, M., Gandini, A., Fabbri, P., Belgacem, M.N. (2004) Modification of cellulose fibres with organosilanes: under what conditions does coupling occur. J. Colloid Interf. Sci. 273:505-511.

Directive 2004/42/CE (2004) Official Journal of the European Union $143 / 87$.

EN 311 (2002) Wood-based panels. Surface soundness. Test method.

EN 927-3 (2006) Paints and varnishes. Coating materials and coating systems for exterior wood. Natural weathering test.
Freeman, M.H., Shupe, T.F., Vlosky, R.P., Barnes, H.M. (2003) Past, present and future of the wood preservation industry. For. Prod. J. 53:8-15.

Hjort, S., Bok, G. (2010) Folksams Färgtest-3, Volume 1005, Swerea IVF-Report, Göteborg University.

Preston, A.F. (2000) Wood preservation: trends of today that will influence the industry tomorrow. For. Prod. J. 50:12-19.

Rasmussen, J.S., Barsberg, S., Felby, C. (2013) Complex between lignin and a Ti-based coupling agent. Holzforschung 68:541-548.

Schultz, T.P., Nicholas, D.D., Preston, A.F. (2007) A brief review of the past, present and future of wood preservation. Pest Manag. Sci. 63:784-788.

Underhaug, A., Lund, T.J., Kleive, K. (1983) Wood protection - the interaction between substrate and product and the influence on durability. J. Oil Colour Chem. Assoc. 11:345-350. 
Williams, R.S., Plantinga, P.L., Pemela, L., Feist, W.C. (1990) Photodegradation of wood affects paint adhesion. For. Prod. J. 40:45-49.

Williams, R.S., Sotos, P., William, C.F. (1999) Evaluation of several finishes on severely weathered wood. J. Coat. Technol.

71:97-102.
Xie, Y., Hill, C.A.S., Xiao, Z., Militz, H., Mai, C. (2010) Silane coupling agents used for natural fiber/polymer composites: a review. Composites Part A 41:806-819. 